\title{
Intentionality as a Conceptually Primitive Relation
}

\author{
Dale Jacquette
}

Received: 21 June 2010 /Accepted: 14 December 2010/Published online: 19 January 2011

(C) Springer Science+Business Media B.V. 2011

\begin{abstract}
If conceptual analysis is possible for finite thinkers, then there must ultimately be a distinction between complex and primitive or irreducible and unanalyzable concepts, by which complex concepts are analyzed as relations among primitive concepts. This investigation considers the advantages of categorizing intentionality as a primitive rather than analyzable concept, in both a historical Brentanian context and in terms of contemporary philosophy of mind. Arguments in support of intentionality as a primitive relation are evaluated relative to objections, especially a recent criticism by Jerry A. Fodor. Against this background, the relation between qualia and intentionality in the understanding of consciousness is explored.
\end{abstract}

Keywords Brentano, Franz · Conceptual analysis · Fodor, Jerry A. · Intentionality · Logic $\cdot$ Semantics

\section{What Is Intentionality?}

We begin for historical and ideological reasons with Franz Brentano's concept of intentionality. Brentano in the late nineteenth century is arguably the most radical and enthusiastic defender of the theory of intentionality that we shall develop, and from whom we derive our philosophical inspiration. Brentano's doctrine states that all and only psychological states are intentional. By this he means among other things that psychological states are related in real-time instantiation to precisely the objects that are considered in each thought, toward which objects the thoughts are directed or what they are said to be about. Intentionality is thus the 'aboutness' of living thoughts in the first instance, and of the expressions of thoughts in purposeful language, art and artifacts, that can continue to carry some of the meaning of the thoughts expressed far beyond the shelf-life of their originating intentionalities. We

D. Jacquette $(\bowtie)$

Institut für Philosophie, Lehrstuhl für theoretische Philosophie, Unitobler, University of Bern,

Länggassstrasse 49a, CH-3000 Bern 9, Switzerland

e-mail: dale.jacquette@philo.unibe.ch 
find intentionality instantiating an aboutness relation in every thought, if Brentano's thesis is correct, and expressively in the world when thoughts are communicated or otherwise embodied to preserve meaning in concrete expression even after the more ephemeral living thought itself has passed, and for as long as its expression persists.

Brentano, as even his title indicates, observes an empiricist methodology in his (1874) Psychologie vom empirischen Standpunkt. As a philosophical admirer especially of David Hume and John Stuart Mill, Brentano does not venture, at least when investigating psychology from an empirical standpoint, beyond what the available empirical evidence can support. The empirical evidence of inner perception (innere Wahrnehmung) for Brentano no more implies that the intended objects of thoughts are determined by thought's inner perception of its own structures and content than Hume's consideration of his empirical experience implies the existence of an external world existing outside of thought, or, in George Berkeley's phrase, "without the mind". ${ }^{1}$ Equally, neither Hume nor Brentano would assert the contrary thesis that there is no external world corresponding to but independent of sensation and perception, and, in Brentano's case, of intended objects transcending the mental acts of believing, doubting, expecting, loving, hating, hoping, fearing, anticipating, and the like, as beyond the contents of any such thoughts. Brentano's early 'immanent' or 'in-existence' intentionality thesis implies that intended objects are literally contained within and as such are phenomenologically indistinguishable from the contents of thoughts by which they are intended.

Thus, when Brentano famously says that in loving something is loved, he means to claim that all we can say from an empirical standpoint in descriptive philosophical psychology is that the beloved intended object of a mental act of loving cannot be distinguished from the content of the thought featuring the mental act in which the object is loved. ${ }^{2}$ Brentano leaves it at that, because he has no sound empirical basis in inner perception for deciding that the intended object is ever distinct from the thought content in which the object is presented to consciousness. As a good empiricist, he does not try to speculate about what might exist beyond what reflection on the contents of experience can responsibly discover. ${ }^{3}$

The point of a disciplined empiricism like Hume's, to which Brentano in 1874 evidently aspires, is to offer philosophical judgment only on propositions for which there exists sufficient decisive empirical evidence, and not to try to squeeze more metaphysical juice especially from sense experience than, as a hypothesis of what

\footnotetext{
${ }^{1}$ George Berkeley (1998), A Treatise Concerning the Principles of Knowledge, especially Part I, §1-24, p. 103-111, in which Berkeley explains his object of inquiry and the methodology he proposes to follow. Philonous in Berkeley's Three Dialogues Between Hylas and Philonous is equally fond of criticizing the possibility of existence 'without the mind', by which we learn he does not merely mean finite human minds, but specifically includes God's divine 'infinite' mind, and which he offers to prove by at least two arguments from his rigorous and uncompromisingly idealist empiricism.

2 Brentano, Psychologie vom empirischen Standpunkt, (1874, p. 115): "Every psychic phenomenon is characterized by what the Scholastics of the Middle Ages called intentional (also indeed mental) inexistence of an object, and which we, although not with an entirely unambiguous expression, will call the relation to a content, the direction toward an object (by which here a reality is not understood), or an immanent objectivity. Every [psychic phenomenon] contains something as an object within itself, though not every one in the same way. In presentation something is presented, in judgment something acknowledged or rejected, in love loved, in hate hated, in desire desired, and so on" (my translation).

${ }^{3}$ See Jacquette (2001 and 2002).
} 
Hume called 'the experimental Method of Reasoning', can be justified by a scientific method of hypothesis formation and testing through empirical observation and experiment. ${ }^{4}$ Hume and Brentano both maintain that philosophy to be worth its salt must become scientific. In both cases their manifestos are issued on the cusp of the failure of rationalist philosophical methodologies, in the seventeenth century from which Hume's Scottish Enlightenment thought emerged, and in the a priori rationalist post-Kantianism that had publicly exhausted its resources and ideological momentum even before Brentano in effect declared that it was time to go back from Plato and Kant to Aristotle and Hume.

Brentano, true to his background commitment to a scientific philosophy, influenced by Humean empiricism, is able on the basis of innere Wahrnehmung to distinguish in every thought between a mental act and its content. Precisely like Hume again, however, Brentano has no sound experiential grounds on which to distinguish a thought's intended object from its content. Anything else, to say, for example, that the intended object transcends the thought by which it is intended, being about something beyond the contents of a thinker's thoughts, the planet Mercury itself, for example, rather than the contents of thoughts about the planet, would constitute a betrayal of the limits of Humean empiricist philosophical methodology. As testimony to this principled constraint on speculative metaphysical theorization, we note that in A Treatise of Human Nature (1739-1740), Book I, Part II, Section VI, "Of the idea of existence, and of external existence", Hume argues that:

" $[\mathrm{N}] \mathrm{o}$ object can be presented resembling some object with respect to its existence, and different from others in the same particular; since every object, that is presented, must necessarily be existent. / A like reasoning will account for the idea of external existence. We may observe, that 'tis universally allow'd by philosophers, and is besides pretty obvious of itself, that nothing is ever really present with the mind but its perceptions or impressions and ideas, and that external objects become known to us only by those perceptions they occasion." 5

Later, in Part IV, Sect. II, "Of scepticism with regard to the senses", Hume concludes that philosophy is incapable of rigorously proving the existence of an external reality beyond the contents of thoughts, even if the passions and in particular the imagination is psychologically compelled to accept the existence of a real world positively corresponding to our Impressions and Ideas. "We may well ask," Hume adds, "What causes induce us to believe in the existence of body? but 'tis in vain to ask, Whether there be body or not? That is a point, which we must take for granted in all our reasonings." 6

Previously, in the context of considering counter-objections to his critique of the idea of a true vacuum, in Treatise, Part II, Section V, Hume revealingly replies to the following criticism: "'Twill probably be said, that my reasoning makes nothing to

\footnotetext{
${ }^{4}$ See the original title page of Hume's Treatise (reference immediately below): A Treatise of Human Nature: Being an Attempt to introduce the experimental Method of Reasoning into Moral Subjects.

${ }^{5}$ David Hume (1978, p. 67).

${ }^{6}$ Ibid., p. 187.
} 
the matter in hand, and that I explain only the manner in which objects affect the senses, without endeavouring to account for their real nature and operations." "7 Hume takes the opportunity to stand firm on the limitations of his methodological commitments: "I answer this objection, by pleading guilty, and by confessing that my intention never was to penetrate into the nature of bodies, or explain the secret causes of their operations. For besides that this belongs not to my present purpose, I am afraid, that such an enterprize is beyond the reach of human understanding, and that we can never pretend to know body otherwise than by those external properties, which discover themselves to the senses." 8

If Brentano, as it seems, is trying to follow a late Hume- and Mill-influenced British empiricist methodology, then it is understandable why he should have adopted the controversial 'immanent' intentionality thesis, or thesis of the 'inexistence' of intended objects. Brentano's immanent intentionality thesis in this regard is no more or less radical an empiricism, applied in his instance to descriptive psychology or phenomenology (later to be developed by Brentano in his lectures on Deskriptive Psychologie as 'Psychognosie'), than one finds for example in Berkeley or Hume. By this principle, Brentano, motivated perhaps by Hume but represented in psychological research more pertinent to Brentano's immediate interests by such figures as Mill, Alexander Bain and Gustav Theodor Fechner, and self-consciously related historically more ultimately to Aristotle's scientific approach to philosophy as reflected in Brentano's prior monographic studies of Aristotle's metaphysics and psychology, signals that psychology as an empirical science has no business speculating on the existence of intended objects outside the phenomenal contents by which they are admitted to thought. ${ }^{9}$

Brentano's original imminence or in-existence intentionality thesis was roundly rejected by Brentano's own students, especially Alois Höfler, Alexius Meinong, and Kazimierz Twardowski, as well as Edmund Husserl. ${ }^{10}$ They understood the importance of the proposition that all thought is intentional, and that inner perception reveals an intentional act-content-object structure. What they were unwilling to accept is the kind of empiricism that requires philosophy to be ontically neutral about the transcendence of intended objects on the grounds alone that thought cannot get outside itself to compare its inner contents with an outer reality of potentially intended objects. Brentano's followers gravitated naturally instead away from Hume's Pyrrhonian ontic skepticism and closer to a version of Aristotle's naïve realism of primary substances. They were prepared with Aristotle to accept the existence of a world of objects available for mental acts to intend that transcend the thoughts themselves by which they are intended and exist objectively outside the mind. The loyalty of Brentano's students to the intentionality thesis in its most general terms and their revolt from Brentano's own early immanent or inexistence intentionality thesis is in this sense a turn away from Humean to Aristotelian empiricism, a move for which Brentano might have had been expected to have more sympathy than in the event he actually demonstrated.

\footnotetext{
${ }^{7}$ Ibid., p. 63 .

${ }^{8}$ Ibid., p. 64.

${ }^{9}$ Franz Brentano (1995, especially p. 3, p. 5, p. 10, pp. 15-17, pp. 32-36, pp. 135-139, and Appendix 5).

${ }^{10}$ See my more detailed discussion of the history of Brentano and some of his school in Dale Jacquette (1991).
} 


\section{Proposed Intentionality Thesis}

A neo-Brentanian intentionality thesis tracks the precedent set by Brentano's students in adopting the proposition that all thoughts intend or are about objects, while denying that intended objects as a rule are indistinguishable from the contents of the mental acts by which the objects are intended. We say, informally:

\section{INTENTIONALITY}

Every thought is about something, in the sense that every sensation and mental act of consciousness or self-consciousness intends an object. Some objects, in the case of self-reflective thinking, may belong immanently to their intending thoughts, as when we self-consciously think about the content of an occurrent thought, in which case the content of a thought may turn out to be indistinguishable from its object. In other cases, typified but not limited to perception, intended objects transcend the thoughts by which they are intended to include objectively existent real world entities, abstract objects, and even irrealia in a distinct intentional mind-independent referential domain.

The proposed intentionality thesis by itself does not imply anything genetic about where intentionality comes from, how it emerges as the defining characteristic of thought, or anything whatsoever about the metaphysics of intentionality and intentional relations. We suppose that intentionality is an abstract relation like others that comes to be instantiated when its necessary and sufficient conditions are satisfied, for example, by a sufficiently articulated central nervous system minimally capable of sensation and hence of sensing something, an intended object of the realtime thought of an actual thinking subject.

If intentionality is such a relation, and if its conditions for instantiation can be satisfied by the evolutionary development of thinking subjects such as ourselves among other animals, in that moment, when as Arthur Schopenhauer says, the first insect (but why an insect?) opens its eye (and where did the eye come from?), then intentionality need be no more metaphysically puzzling than other kinds of abstract relations that are real-time-instantiated when their conditions are satisfied by circumstances in the actual world. ${ }^{11}$ Such property instantiations can include that of being chordate, of having a backbone, which must have emerged evolutionarily as part of our early biological heritage many millions of years ago. Or, to choose another kind of example to illustrate the diversity of possibilities, the property of being $120 \mathrm{~cm}$ in height. Here we find another abstract relation whose explicit condition can be satisfied over a span of time by a growing human being at a certain age.

Intentionality abounds for thinking, socially communicating subjects such as ourselves. We are surrounded with it in the sense that unless we live without any technology, even such as Adam and Eve fashioned for themselves out of vine leaves when they knew that they were naked, then our lives are largely conducted within a

\footnotetext{
${ }^{11}$ Arthur Schopenhauer, The World as Will and Representation (1966, vol. 1, p. 30): "And yet the existence of this whole world remains for ever dependent on that first eye that opened, were it even that of an insect. For such an eye necessarily brings about knowledge for which and in which alone the whole world is, and without which it is not even conceivable."
} 
human-made environment in which natural substances and forces of nature are exploited that reflects practically countless intentions by untold numbers of persons involved in the planning, design, procurement of materials, manufacture, maintenance, and so on, of the artificial world of artifacts, shelter, furniture, vehicles for conveyance, institutions and services that we inhabit and whose tools and toys we use for our own evolving purposes. If we think at all, then, according to the proposed intentionality thesis as for Brentano's original version, we think about something, and our thought intends an immanent or transcendent object. Intentionality in inner perception or phenomenological reflection in turn seems generally to be transacted by means of a mental act and with an accompanying content that notably includes what philosophy of mind today sometimes refers to as the qualia of experience, but that Brentano and his school spoke of simply as 'content' (Inhalt).

\section{What Would it Mean for Intentionality to Be a Conceptually Primitive Relation?}

To propose as we shall now do that the intentionality relation mentioned in the above mixed immanent and transcendent intentionality thesis is conceptually primitive means that there are no more basic concepts than intentionality within our conceptual network to which the concept of intentionality might be reduced or by means of which it might be analyzed (although there could also be and undoubtedly are other concepts besides intentionality, concepts of physics and mathematics, metaphysics, and others that are equally conceptually primitive).

If intentionality is a conceptually primitive relation, then there are no more basic concepts by means of which the concept of intentionality can be understood. The model is one in which there are both complex and simple concepts. Philosophical analysis has as its first task to distinguish these in the process of trying to define any interesting concept into more basic concepts, if possible, and if not, then beginning to think of the historically irreducible and unanalyzable concepts as likely to be conceptually primitive. We use whatever sound logical tools are at our disposal in the effort to provide an unambiguous intuitively correct conceptual analysis of whatever concepts we can in a process of clarifying our thoughts and better understanding the nature of thought. We learn as much from interesting mistakes in philosophical analysis, although we learn different kinds of things, as we do from a more widely accepted bullet-proof analysis of a philosophically interesting concept that might be proposed. We can reductively analyze the complex concept of knowledge into some type of justified true belief or the concept of bachelorhood into adult unmarried male, and no doubt the properties of being justified, true, a belief, adult, unmarried, male, and the like, might in turn be yet more reductively analyzed, or judged already conceptually primitive.

Ultimately, we decide these matters according to whatever concepts we believe are needed for our explanations. They are the concepts that experience and external argument strongly justify as being capable of further analysis, involving logical constructions out of more basic defined or conceptually primitive, undefined and undefinable concepts. If we are playing the foundational conceptual analysis game at all in philosophy, and the value of doing so in understanding philosophical 
problems in their exact meanings cannot be overstated, then we must expect to encounter primitive concepts of one sort or another at the bottom of every correct analysis. It is only a question then of the particular concepts to regard as primitive and the arguments that can be given for regarding one choice over another as conceptually further unanalyzable. If we are not interested in understanding philosophical problems in their exact meanings, then either we are not interested in doing philosophy in the first place, which it is no one's moral obligation to pursue, or else we must produce a reductive analysis of the concept of intentionality into at least comparatively more basic concepts. If such analysis cannot be produced, as is historically the case after a variety of valiant attempts with respect to the concept of intentionality, then it is only philosophically responsible to question whether or not intentionality in particular is a conceptually primitive concept of our conceptual network. We are entitled then to consider that perhaps intentionality is a concept in terms of which other concepts of cognitive, emotional, and other psychological states can be defined, as when we explicate the meaning and purpose of art and literature and artifacts generally, but that in itself is incapable of reductive conceptual analysis into more basic concepts with the aid and within the constraints of an appropriate logic.

The same should be true even if we adopt a coherence net instead of a foundational model of conceptual analysis. In a coherence net there are also local stratifications of concepts related to other concepts at different levels of abstraction; there are just no global hierarchical, which is to say foundational, stratifications of absolutely conceptually primitive concepts as the simplest building blocks from which to build conceptually more complex concepts and to which all conceptually complex concepts can ultimately be reductively analyzed. We can still locally hierarchically define knowledge as justified true belief, where we think that, comparatively speaking, the concept of knowledge seems less basic than the semantic, epistemic and doxastic concepts of truth, justification and belief, even if we do not suppose one way or the other that being justified, true, or believed are concepts that are either themselves conceptually primitive or complex. We need not make up our minds as to whether truth, justification, and belief are capable of being further reduced in meaning to a conceptual foundation of conceptually primitive reductively unanalyzable concepts, in order to allow that, even within a nonfoundational coherence net of concepts, the concept of knowledge can be reductively analyzed as justified true belief, regardless of the analytic status of justification, truth, and belief, or of any other lateral or more basic concepts. If there is any local hierarchy within a coherence net model of conceptual analysis, then there are some concepts that are conceptually analytically more basic than others. This is all that we need for present purposes in suggesting, even hypothetically in lieu of absolute conceptual foundations, that intentionality is a conceptually primitive concept in our conceptual net in the sense that within the net it is incapable of being further reductively analyzed in terms of any more basic concepts.

If no concepts are more basic than others in an imagined coherence net, then it will still be true that intentionality is conceptually primitive in the relevant sense of being incapable of reductive analysis into more basic concepts, because in that case there simply are no more basic concepts. The trouble then is that we must countenance a model in which all concepts are conceptually primitive. Such a 
conclusion eliminates much of the theoretical interest in distinguishing primitive concepts as somehow bringing us closer to understanding the real nature of things. It also leaves us with the embarrassment of accounting for apparent hierarchical reductive analyses of concepts typified by the hackneyed conceptual analyses of knowledge and bachelorhood, of the fact that even in science the concepts of physics seem conceptually more basic, for example, than the concepts of biology. Whether conceptual analysis is foundational or coherent, we project that at least many if not all biological concepts, any that deal with concepts of the spatiotemporal properties of living things, will be conceptually reductively analyzable with the help of logic into the conceptually more basic concepts of physics.

The present inquiry is to ask whether intentionality should be judged a conceptually primitive reductively unanalyzable concept in terms of which other more complex concepts can be defined, but which is itself incapable of being reductively analyzed into any logical structure of more basic concepts. Anticipating a positive answer to this question, we consider the implications of such a proposition for logic, philosophy of mind, semantics and philosophy of language, aesthetics, philosophy of art and art criticism, and related philosophical subdisciplines and practices.

An important implication, to give a sense of what is at stake in the question as to whether intentionality is or is not a conceptually primitive reductively unanalyzable concept in our conceptual scheme or net, foundational or coherence, is that if there is no reductive conceptual analysis of the concept of intentional relations to any logical structure of purely extra-intentional concepts, then a fortiori there is no causal or other physicalist reduction of intentionality to the extra-intentional. Under the proposed intentionality thesis, according to which all thought is intentional, it follows immediately in that case that there is no causal or other physicalist reduction of thought. The problem in less universal terms affects whatever proper part of all thoughts we may agree to be genuinely intentional, even if we do not agree with the proposed intentionality thesis that all and only thought is intentional.

\section{Fodor's Objection}

Jerry A. Fodor frontally attacks the idea of categorizing intentionality as conceptually primitive. In his (1987) study, Psychosemantics: The Problem of Meaning in the Philosophy of Mind, Fodor considers:

"I suppose that sooner or later the physicists will complete the catalogue they've been compiling of the ultimate and irreducible properties of things. When they do the likes of spin, charm and charge will perhaps appear on the list. But aboutness surely won't; intentionality simply doesn't go that deep. It is hard to see, in face of this consideration, how one can be a realist about intentionality without also being, to some extent, a reductionist. If the semantic and the intentional are real properties of things, it must be because of their identity with (or maybe of their supervenience on) properties that are themselves neither intentional nor semantic. If aboutness is real, it must really be something else."12

$\overline{12}$ Jerry A. Fodor (1987, p. 97). 
Fodor's objection represents a widely held view about the concept of intentionality as somehow not a part of the natural order of things. The criticism he offers nevertheless fails on several grounds. Fodor assumes in his first sentence that it is up to the physicists to decide on the list of the "ultimate and irreducible properties of things". Naturally, physicists are not going to include intentionality on such a list unless intentionality is a purely physical property. However, if intentionality were a purely physical property, then it would not be conceptually primitive, for there would exist an intuitively correct analysis of the complex concept of intentionality into the supposedly more basic concepts of physics. No reductive analysis of the concept of intentionality to any other concepts, especially those of pure physics, historically has as yet succeeded, and there are good reasons to think that no such reductive analysis could possibly succeed. Intentionality is in any case invisible to physics, something that is not within its competence to consider. We are fortunately under no obligation to allow matters of what is or is not conceptually primitive to be decided by physicists alone, or for that matter by authoritative researchers in any other particular branch of experimental inquiry. The conceptual status of intentionality as primitive or reductively analyzable is a challenge specifically for analytic philosophy, which in the process needs to understand developments in, among others, physics and psychology, neurophysiology and the behavioral and information sciences.

More importantly, it is altogether unclear what Fodor means by speaking of intentionality as not being as 'deep' as spin, charm, and charge. The test of what is or is not theoretically irreducible in our understanding of the world as a whole, of what is deepest within our conceptual scheme, is whether or not there is anything more basic from which a concept can be derived or to which it can be explanatorily reduced. If a concept is such that our explanations are incomplete or incorrect when we try to get by without it, and such that we cannot replace it with any conceptually more fundamental kind or category of concept, then the concept in question is indeed conceptually primitive or analytically irreducible and as 'deep' as any it may be possible to find among the concepts needed to explain the world.

Nor is Fodor on the right track when he claims that intentionality could not be among the basic irreducible properties of the world by virtue of supervening on purely physical properties. To deny that intentionality supervenes on the physical would be to make intentionality something supernatural, rather than a natural property of functioning neurophysiological systems belonging to certain kinds of thinking subjects understood as complexly organized living things. Intentionality is surely a natural rather than supernatural property. It has arisen as a property of certain animals through evolution by natural selection, and most of them possess it at least at a primitive level of sensation or voluntary motor control. If, however, as we have also maintained, intentionality is conceptually primitive, then it presumably supervenes on a psychological subject's neurophysiological processes for reasons that cannot be adequately explained in terms of purely extra-intentional concepts. It follows further then that intentionality, despite naturally supervening on properly organized physical substances and causally related events, is also an irreducible property in its own right, with precisely the same conceptual or corresponding metaphysical depth as any of the most fundamental physical properties by which the universe is constituted. 
When Fodor concludes by saying "If aboutness is real, it must really be something else", he is perhaps closer to the truth than in his preceding remarks. It rather depends on exactly what Fodor means by this pronouncement, which in the present context is not entirely clear. Intentionality or the aboutness of thought, true enough, is something else; something other than the world's purely physical properties and processes. We recognize that aboutness is a different kind of natural property than the purely physical properties mentioned by Fodor. If we regard intentionality as a conceptually primitive concept, then the mind's intentionality in particular is behaviorally-materially-functionally ineliminable and conceptually irreducible and unanalyzable. Fodor's observations on the conceptual status of aboutness in fact appear confused. If intentionality were an ultimate and irreducible property in the same sense as such basic physical properties as spin, charm, and charge, then, paradoxically, intentionality would and could not be conceptually ultimate in the sense of being physically irreducible. Intentionality would then instead be just another physical property, precisely on a par with spin, charm and charge. However, just as spin, charm, and charge are not reducible to one another if they are distinct ultimate and irreducible physical properties of the world, so intentionality cannot be reducible to any combination of these factors if it is an ultimate and irreducible extra-physical emergently supervenient property. That is nothing other than what it means for the concept of intentionality to be conceptually primitive, conceptually irreducible and unanalyzable. A critic of the thesis that intentionality is conceptually primitive or reductively unanalyzable, accordingly, can hardly argue, as Fodor seems to do, that the concept of intentionality cannot be conceptually primitive because intentionality is not a purely physical concept. ${ }^{13}$

\section{Implications of the Intentionality as Conceptually Primitive Thesis}

We now consider some of the philosophically most important implications of the proposal to categorize intentionality as a conceptually primitive relation.

\section{Philosophy of Mind}

We have already suggested that if the proposal that intentionality is conceptually primitive is true, then it has among its implications the consequence that if there is generally no satisfactory conceptual reduction of the concept of intentionality to any more basic concepts, then in particular there is also no satisfactory conceptual reduction of the concept of intentionality to purely physical concepts.

The further implications of intentionality as a conceptually primitive relation for the mind-body problem in philosophy of mind should now be obvious. It must follow in that case that in some sense mind $\neq$ body, so that metaphysics becomes tasked with explaining how the two must differ and what their difference means. Property dualism is recommended as a solution to the mind-body problem by the fact that the mind has, while the body considered only as a purely physical entity

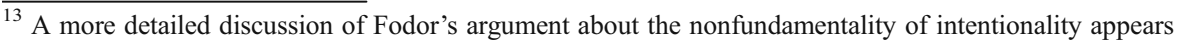
in Jacquette (2009, pp. 143-145).
} 
does not have, intrinsically intentional relations essential to all or at least to certain kinds of thoughts. The mind supervening on the brain and nervous network has both purely physical and intentional properties, and if intentional properties are irreducible to purely physical properties, then the body considered as a purely physical entity cannot be identically the same thing as the mind.

The mind, after all, as Socrates believed and René Descartes tried but failed to prove, is distinct from the body, not by virtue of the mind being 'better' or 'more easily' knowable than the body, or by the body unlike the mind being divisible into self-sufficient like continuant parts, but by virtue of the body's being purely physical and the mind, thanks to its intentionality, not being purely physical, but possessing a property that, as itself conceptually primitive, cannot be reduced to any more basic concepts, and in particular not to any more basic purely physical concepts.

\section{Philosophical Logic and Semantics}

The meaning of a singular referring expression or complete sentence is determined by the intentions of thinkers with whom the meaning of the thought or its expression originates. Logic and semantics consequently cannot be purely extensional, but must rather be intensional in adequately linguistically representing the conceptually reductively unanalyzable intentionality of thought. Purely formal semantics in which abstract 'mappings' of words onto objects are projected without thinking subjects doing the mapping are demonstrably inadequate. The naming of objects and the predication of properties to named objects begins with the intrinsic intentionality of thought reflected derivatively in its expression.

This result further implies that in logic and philosophical semantics we must begin intensionally with properties rather than extensionally with existent objects. An intensionalist logic and semantics founded on an intentionalist philosophy of mind makes it possible to define objects independently of their ontic status in terms of their bearing a particular sometimes metaphysically incompatible complement of individually logically possible properties. The advantage of an intensional approach to logic and semantics, favored by the intentionality thesis and the proposal that intentionality is a conceptually primitive reductively unanalyzable relation, is that we can make sense of thought and language intending both existent and nonexistent objects, where the identity conditions for an ontically mixed referential domain of all intended objects are provided by each unique combination of logically possible properties. We thereby make sense of the Brentano-inspired intentionality doctrine according to which every thought intends an object, when it is clear that not every thought intends or is about an existent object, but about any object that might be described as the possessor of a certain set of properties.

The further implications of the proposition that intentionality is a conceptually primitive relation for philosophical logic and semantics are as interesting as the formal details, which require more space and preparation than can be allowed them here. Explorations of intensional logics are found in various formulations supporting various formal and philosophical interpretations. Intentionality-friendly intensional logic and semantics have also been developed and await further even more interesting formal results and practical applications. Domain comprehension and interpretation of the quantifiers and quantifier-bound variables, based on a compatible theory of reference, identity, and deductively valid inference, are among the differences between classical 
extensional and intensional logics and semantics supported by the thesis of intentionality as a conceptually primitive relation. ${ }^{14}$

\section{Freedom of Will and Moral Responsibility}

If all action depends on decision, and if a decision to do something involves an intentional relation between a thought and an as yet unrealized and possibly interminably inactual nonexistent state of affairs, then, if intentional relations are conceptually primitive and hence irreducible to purely physical states of affairs involved in causal relations, then decisions and actions based on decisions to act will not be fully physically or causally explicable.

The nonexistent states of affairs that generally stand as intended objects of decisions to act at the time when the decisions are made are essential components of the explanation of any decision to act and the action that usually follows. When I choose to make a sandwich it is not (yet and may never) actually case that the sandwich I propose to make exists. It will exist only if I am successful in my attempt to make the sandwich, but the sandwich, despite being a nonexistent intended object of my decision and desire to act, is indispensable to the explanation of my action. Why otherwise do I slice bread, retrieve the turkey, mustard and bean sprouts from the refrigerator, and do all the other things I do that result in a sandwich's being prepared? Nonexistent states of affairs are nevertheless causally inefficacious since they lack any actually instantiated physical properties. The complete explanation of a future-directed decision to act and the action if any that issues from it, therefore, cannot be purely physical or causal, and hence the phenomenon of decision-making and action cannot be conceptually reductively analyzed in purely physical or causal terms. Decisions to act and the actions that sometimes occur as a consequence are therefore causally undetermined; the will and action as intentional occurrences, accordingly, are contracausally free, and as such they are events for which we as free agents can intelligibly be held morally responsible.

\section{Ethical and Aesthetic Value}

Value in an intentionalist philosophy can be theorized as originating with the intending thought of a thinking subject who considers the morality of an action or decision to act, or who aesthetically appreciates an object of art or nature. Ethical and aesthetic value judgments can be understood as relating two objects, the object of moral consideration or aesthetic appreciation, and another object, a positive or negative moral or aesthetic value. This is roughly the proposal for an intentionalist value theory advanced by Brentano's student Alexius Meinong and, in much greater detail, by his Graz school student Stephan Witasek. A detailed discussion of such an intentionalist theory of value can be found elsewhere, but suffice it to say for the moment that the irresolvability of value conflicts can in part be explained by the irreducible subjectivity of valuating intentions, along with the so-called no accounting for taste principle or de gustibus non est disputandum. ${ }^{15}$

\footnotetext{
${ }^{14}$ I contrast extensional with intensional logical and semantic formalisms in Jacquette on "Intensional versus Extensional Logic and Semantics" (2010a, Chap. 5, pp. 97-140).

${ }^{15}$ See Jacquette (2010b, pp. 53-86).
} 


\section{Why We Should Consider Intentionality to be a Conceptually Primitive Relation}

Now that we have explained the meaning and briefly outlined some of the more conspicuous implications of the proposed intentionality thesis and interpretation of intentionality as a conceptually primitive relation, we turn to the question of why we should consider intentionality to be a conceptually primitive relation. There is a package of interrelated conclusions that follow if we accept the proposed revisionary Brentanian intentionality thesis and categorize intentionality as conceptually primitive. If perceived as theoretical advantages, such consequences might already be enough to promote the combined thesis that all or anyway much thought is intentional and that intentionality is a conceptually primitive relation.

Additional arguments in support of intentionalism so defined can be identified as belonging to at least four types. (1) We can argue defeasibly for just such an intentionalism from the historical failure of efforts at reductive conceptual analysis of intentionality to any other more basic concepts and of intentional relations themselves as something purely physical or otherwise adequately expressible in a purely extensional philosophical logic and semantics. (2) From the phenomenological irreducibility of intentional attitudes in a Wittgensteinian thought experiment. (3) On the grounds that interpreting intentionality as conceptually primitive provides a unified integrated philosophy of mind and the expression of thought in language, art, and artifacts, freedom of action and the will, and, as a further bonus, with distinct explanatory advantages over eliminative and reductive approaches to intentionality and the kinds of explanations or explainings-away they are then forced to give of such common intentional phenomena as the immediate meaning of the sentences in a newspaper article, let alone the meaning of Picasso's Demoiselles d'Avignon, or, say, Whitehead and Russell's Principia Mathematica. (4) The proposition that there is no possible conceptual analysis of intentionality because it is a conceptually primitive relation, as we have emphasized, logically implies that there can be no adequate causal or physical reduction of intentionality to purely causal or physical concepts. This proposition gains justification for its truth also in the fact that it independently confirms a result we should anyway expect on the basis of reasons (1)-(3) above, that no adequate causal or physical reduction of intentional to purely causal or physical concepts should be expected as forthcoming. Regardless of advances made in cognitive and other methodologically hard psychological sciences outside the orbit of phenomenology, we should regard the deliverances of private inner observation and experimentation rather than public externalist scientifically respectable perception to be essential to whatever data can be recorded for hard scientific study outside the thinking subject's putatively impenetrable subjectivity. We shall now say something briefly about each of these four categories of arguments for the combined proposition that all or much thought is intentional and that intentionality is a conceptually primitive relation.

\section{Historical Failure of Reduction Attempts - Argument 1}

So far, despite heroic efforts, no one has produced an adequate reductive conceptual analysis of intentionality, let alone a causal, physical, or other 
purely extensional analysis. There are interesting attempts, but none that succeeds in analyzing the concept of intentionality into something purely nonintentional that fills all the legitimate explanatory obligations that are otherwise satisfied by a theory of thoughts being about something, of intending objects.

Interesting admissions concerning attempts reductively to analyze intentionality into purely non-intentional concepts expressible in a purely extensional idiom reinforce the objection that no satisfactory reductive analysis of the concept of intentionality has yet to be advanced. Herbert Feigl, for example, reflects back on his previous attitude toward the conceptual reducibility of intentionality in particular to purely physical or causal concepts of purely physical or purely causal relations, in this connection, in the later "Postscript after Ten Years", to his (1957) classic, The 'Mental' and the 'Physical': The Essay and a Postscript:

"I still agree, of course, with Wilfrid Sellars, Roderick Chisholm, Stephan

Körner, and others, in considering clearly intentional (in Brentano's sense)

features as irreducible to a physicalistic description."

Remarkably, thereafter, however, Feigl continues:

"But...this does not seem to me a serious flaw in physicalism."16

If physicalism is supposed to be the philosophical ideology according to which the mind is purely physical, if thought is at least sometimes intentional, and if intentional relations are as Feigl rightly acknowledges "irreducible to a physicalistic description", then it is hard to see what more serious flaw physicalism could possibly contain. The only recourse for Feigl is to discount the importance of intentionality in philosophical explanations of psychological phenomena, and something like this seems, in fact, to be part of his retrospective outlook on his prior discounting of intentionality as a thorn in the flesh of any conceptually reductive physicalism in the philosophy of mind.

Feigl tries to blunt the force of a primitive reductively unanalyzable concept of intentionality for a materialist or physical-reductivist scientific philosophy of mind by appealing to a distinction of Sellars, when Feigl continues: "According to Sellars' decisive analysis, this irreducibility is on a par with (if not a special case of) the irreducibility of logical categories to physiological ones." 17 However, Sellars' (unfortunate) comparison of the irreducibility of intentionality with the irreducibility of logical to psychological categories, the longstanding battle over psychologism in logic and semantics, supposedly offers Feigl a way out of the problem. Sellars, nevertheless, is not the most robust intentionalist, and other intentionalists would insist that the problem of psychologism is entirely independent of the question whether as a matter of fact our conceptual net permits the local or global reductive analysis of the concept of intentionality to supposedly more basic concepts, again, whatever anyone might imagine them to be.

\footnotetext{
${ }^{16}$ Herbert Feigl (1967, p. 150).

17 Ibid.
} 


\section{Phenomenological Irreducibility of Intentionality (Wittgensteinian Thought Experiment) - Argument 2}

There seem to be no distinguishing internal psychological occurrences accompanying intending one thing or another by use of the same singular referring expression. When we pay close attention to our states of mind as we switch back and forth using the term ' $A$ ' to refer first to one object and then another, or even to refer first to an object and then to its color or the space it occupies, and so on, we do not discern any distinctive phenomenological accompaniment to intending one thing rather than another by alternating uses of the same name. This in turn suggests that there is nothing within the act of intending to which the act's intentionality might plausibly be conceptually reduced, supporting the thesis that intentionality is most probably a primitive, conceptually irreducible or unanalyzable, concept. Wittgenstein writes, in Philosophical Investigations $\S 33$, to dispel the idea that behavioral ostension is sufficient in itself to communicate the meaning of a name:

"Point to a piece of paper. - And now point to its shape - now to its colour — now to its number (that sounds queer). — How did you do it? — You will say that you 'meant' a different thing each time you pointed. And if I ask how that is done, you will say that you concentrated your attention on the colour, the shape, etc. But I ask again: How is that done?"18

Wittgenstein's thought experiment calls attention to the fact that we do not do anything in order to intend. To concentrate one's attention on the color, shape, location in space, and so on, of an object is first to refer to just that object in thought, prompting Wittgenstein to restate his original question how that act of referring is accomplished. Intending is rather a basic mental act, an action that we immediately perform as an act of will, and not instrumentally by first doing another thing or performing another action as a means to the end of intending. As such intending is irreducible to anything that happens inessentially on one occasion or another to accompany its occurrence.

\section{Unified Integrated Intentionalism - Argument 3}

We appeal in this category of argument to the four previously discussed implications of understanding intentionality as a conceptually primitive relation. These include as consequences the advantages of providing: (a) an intuitive satisfying unified solution to the mind-body problem, as well as a negative stance on the artificial intelligence controversy and the question whether it is possible to program a digital information processing machine to have conscious thought and an inner mental life such as we natural intelligences experience; (b) support of intensional philosophical logic and semantics; (c) interpretation and defense of freedom of the will and moral responsibility for freely chosen actions; (d) interpretation of ethical and aesthetic value. These advantages further recommend the thesis that thought is intentional and intentionality is a conceptually primitive relation as part of an inference to the best explanation of the several phenomena in question.

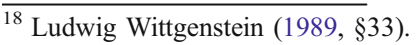




\section{General Conceptual Reductive Unanalyzability Implies Causal Physical Conceptual Reductive Unanalyzability — Argument 4}

If there is generally no reductive conceptual analysis of intentionality to be presented in terms of purely extra-intentional concepts, then a fortiori there can in particular be no causal or other physical reductive analysis of the concept of intentionality to purely extra-intentional concepts. This proposition further agrees with and lends support to the conclusion above that the intentionality of thought impedes a fully reductive analysis of the concept of mind to purely extensional causal or other material or physical concepts in the intentionalist solution to the traditional mindbody problem. The agreement of several intentionalist principles on the mind $\neq$ body conclusion reinforces the consistency of its metaphysics of intentionality and its implications in the philosophy of mind, philosophy of language, art and artifacts, and in advancing an intensionalist philosophical logic and semantics. From the general considerations militating in favor of understanding intentionality as a conceptually primitive reductively unanalyzable relation, we immediately deduce as a special case a conclusion that is highly significant in itself and that lends independent support to a proposition that many philosophers have intuited as true, even when their own arguments for mind-body nonidentity have not always worked.

\section{Qualia and Intentionality in the Philosophical Understanding of Consciousness}

Finally, we consider the implications of the proposed intentionality thesis and thesis of intentionality as a conceptually primitive relation for the problems of sensation and intentionality, Richard Rorty's objection to the intentionality thesis, and David J. Chalmers' argument that intentionality is supervenient on qualia, rather than qualia supervening on intentionality or the two being jointly supervenient directly as peers on the same neurophysiological supervenience base.

What we ultimately want is a philosophy of mind that seems to understand the concept of mind. We want to know theoretically what people are talking about when they refer to their minds, or literally or metaphorically to losing their minds, minding their own business, making up their minds, and the like. We want a theory that either gives us a very good reason for giving up ostensible reference to our minds, convincing us in effect that despite appearances we do not actually have minds, or else explains the existence and properties of mind as we experience the subjective occurrence of our own thoughts.

\section{Rorty's Challenge to the Universal Intentionality of Thought}

An intentionalist in the philosophy of mind may want generally to maintain that every thought, including raw sensation as perhaps the most fundamental category, consists of an unmediated basic mental act of intending an object, often practically managed for purposes of assisting its cognitive operations in memory, reason, imagination, emotion, and motivation, by a logically inessential but psychologically 
useful auxiliary phenomenological content or qualia in the higher-function experiences of consciousness and self-consciousness.

Contrary to the proposed intentionality thesis in its full generality, that all thought is intentional in the sense of involving a conceptually primitive reductively unanalyzable relation in which every thought contains a mental act that intends an object to the accompaniment and oftentimes but not logically necessarily referentially facilitating occurrence of a mental content either with or as entirely constituted by a particular qualia - or, popularly, what it is like to experience a particular kind of mental event, tasting a strawberry or solving an equation or remembering having once solved it - Richard Rorty argues that not all thought is intentional because the experience of pain does not intend or is not about anything. Rorty asks rhetorically about the intended object of pain in his (1979) Philosophy and the Mirror of Nature:

"The obvious objection to defining the mental as the intentional is that pains are not intentional - they do not represent, they are not about anything.",19

Rorty's objection is plausible but arises through a misunderstanding and misapplication of the grammar of intentional relation expressions and the putative intended objects of sensation experiences. Pain does not have an intended object, rather, pain $i$ is the intended object of more generally considered sensations, as when I say in everyday discourse that I have a feeling of pain. ${ }^{20}$

Rorty's objection depends on the mistaken assumption that for any $x$, if $x$ is the content of a thought $T$, then $x$ cannot also be the intended object of $T$. Kazimierz Twardowski seems to believe something like this in his (1894) treatise, Zur Lehre vom Inhalt und Gegenstand der Vorstellung. ${ }^{21}$ The proposition is nevertheless not true in two important respects for all three main categories of thoughts and their intended objects in sensations, conscious and self-conscious experiences. We might argue, in the first place, that pain like all other sensations is both lived-through experiential content (qualia) and intended object of more generalized sensation states. An obvious reference appears in Rorty's own example, where, in feeling pain, feeling is the generalized intentional state, and pain is the lived-through qualia-experiential intended object of the relevant psychological event. There are, accordingly, interpretations under which we can make sense of such thoughts as the experience of pain as intentional in Brentano's sense, if we construe experience generically as the mental act, and pain as the intended albeit passively intended object of the experience of the intended object pain, in which the experience is none other than the painful experience itself of the painful content or qualia of pain. Sensation, indeed, is one of two distinct categories of thought in which content $=$ object.

For these cases alone, Brentano's immanence or in-existence intentionality thesis holds true. For others, if we adopt a naive Aristotelian realism about the relation between the external world and many of our perceptions, psychological states or at least all those that are intentional intend thought-transcending objects outside the

\footnotetext{
${ }^{19}$ Richard Rorty (1979, p. 22).

${ }^{20}$ Jacquette (1985).

${ }^{21}$ Kazimier Twardowski (1977, pp. 29-31).
} 
psychological sphere in a real objective world of existent individual things that are something like Aristotelian primary substances.

Acts of consciousness and reflective self-consciousness, like sensations at the most primitive level of thought, also involve a thought's intending its own experienced lived-through phenomenological content or qualia. Consciousness and self-consciousness is about or intends its own content as object, but it often also intends something more, so that usually its content $\neq$ object. This, after sensation, is the second of two categories in which it is at least logically and conceptually possible that content $=$ object. We should therefore posit a mixed domain consisting of both intended objects that are identical to certain thought contents, including circumstances in which a thought intends its own content, and intended objects that transcend the thoughts by which they are intended. By this largesse we avoid both the too-narrow distinction between mental act, experienced content and intended object in Twardowski's arguments, where content and object are maintained always to be numerically distinct, while preserving the essential Brentanian insight, also cherished by his students even in their transcendental Aristotelian rebellion, that all thoughts intend objects and that all thoughts and the mind as thinking subject are essentially, conceptually primitive and reductively unanalyzably intentional. If all thoughts are intentional, and if intentionality is a conceptually primitive relation, then many interesting consequences begin to follow in philosophy of mind, as in philosophy of logic and language, in contrast with a very different picture of mind and its expression of thought in purely reductionist extensionalist theories of meaning and mind, in which the intentionality of thought, as Fodor would have it, is neither regarded as universal nor as conceptually primitive or reductively unanalyzable. $^{22}$

Rorty overlooks a number of replies that might be made against his objection that pain has no intended object. We have suggested that what Rorty says in observing that pain has no intended object is true enough, as far as it goes, but we have argued that there is another logically possible and equally if not more plausible interpretation of such mental occurrences as the experience of pain in which intentionality is instantiated in the relation between the subject's experience as a mental occurrence and pain as simultaneously both its content or qualia and its intended object. $^{23}$

\section{Chalmers on the Supervenience of Intentionality on Qualia}

In his (1996) study, The Conscious Mind: In Search of a Fundamental Theory, Chalmers proposes that intentional states supervene on qualia, and hence that qualia in some sense are conceptually more fundamental than intentionality. He writes:

"There is no argument analogous to the arguments against the supervenience of consciousness showing that intentionality cannot supervene on physical and phenomenal properties. Indeed, conceivability arguments indicate that inten-

\footnotetext{
$\overline{{ }^{22} \text { See Jacquette (1987 and 2006a). }}$.

${ }^{23}$ G.E.M. Anscombe (1965). A very different approach is adopted by Emmanuel Levinas (1998) in his essay, 'Intentionality and Sensation'.
} 
tional properties must be logically supervenient on these if such properties are instantiated at all, and epistemological arguments lead us to a similar conclusion. So there is no separate ontological problem of intentionality."24

What among several things is interesting about Chalmers' argument concerning the supervenience of intentionality on qualia is that it makes qualia the ultimate foundation of consciousness, with intentionality as ontically dependent on and so in some sense reductively conceptually analyzable on the qualia that constitute a conscious mental state. The trouble for Chalmers is that his burden of proof in arguing that intentionality supervenes on qualia rather than the other way around is to convince us that there is a reductive conceptual analysis of the concept of intentionality to some logical construction or other out of pure qualia concepts. There are nevertheless good reasons why historically no such analysis of intentionality has ever been delivered or even seen from afar.

Take any qualia you please, even that experienced by another species, if you believe you know what that would be like, or of your own thought right at this moment, and reflect that logically there is no reason why the content of your thought, whatever it is, could not be associated with any other imaginable intended object. A thinking subject can have a mental image of the Taj Mahal, for example, whenever thinking about Gödel's proof, or experience the qualia of tasting delicious ripe strawberries whenever thinking about the Taj Mahal. The linkage between the content or qualia of thought and the thought's intended object is tenuous at best, so much so that philosophers have seriously worried about whether or not the world outside the mind could reasonably be expected to bear a positive correspondence to the qualia or thought content of whatever we perceive as the external world in any sequence of cognitive events. There are no logically necessary analytic or a priori knowable connections between any particular qualia and any particular intended objects of thought. We can regularly or irregularly intend the same object to the psychological accompaniment of very different qualia, and we can intend different objects in thoughts with generically identical, generically indistinguishable qualia. We can expect there to be completely unexpected associations of the properties of qualia and the intended objects of any thought, even in our everyday thinking as we plot news events on a mental map of the world or engage in other interpretive and problem-solving reasoning. That historically there is no such reductive conceptual analysis of the concept of intentionality despite heroic efforts suggests if it does not outright imply that intentionality may be a conceptually primitive reductively unanalyzable relation, as we have proposed, and that if so then there are significant implications for the mind-body problem, philosophy of logic and language, freedom of action and the will, and the nature of moral and aesthetic value.

We distinguish three levels of thought, and we say that a mind must minimally have at least one of the lower of all three levels in the following inverted Hegelian pyramid of psychological categories: Sentience at the inverted base of the pyramid; Consciousness supervening on sentience among other things, including the thinking subject's neurophysiological states; and Self-Consciousness supervening among other things on Sentience and Consciousness. Invoking a general concept of intentionality that

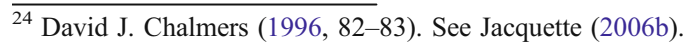


applies to all three plateaus of thought, from sentience to consciousness to selfconsciousness, all of variable degrees, for a spectrum of thinking that extends continuously to the simplest sensing and perceiving animals to the most complex thinking subjects that we know of among our genetic con-specifics, we account for what seems to be at least equi-basic with the qualia of thoughts. We might ask whether an imaginary or actual simple life form could have intentions in the sense of perceiving and hence of perceiving something when they use their senses to gather information about their environment. What we find in human consciousness is something like a refinement of that evolutionarily primitive solution to the problem of surviving and competing genetically with all the other greedy predators. Even so, there is no evolutionary reason to expect that qualia and intended object should positively correspond. We cannot even say that it is evolutionarily expedient as the simplest course for the qualia of our thoughts to descriptively match the features of an external world, since no one is ever in a position to step outside the contents of their thoughts to compare them directly with reality, and this, in turn, because a finite thinking subject can do no more than collect additional qualia when trying to behold reality as though in raw condition independently of thought.

Chalmers' analysis does not go deep enough. It is not true, contrary to Chalmers' unsupported assertion, that there is no argument to show that intentionality cannot supervene on the physical properties or phenomenological content of a conscious state, since some Twin-Earth scenarios in Hilary Putnam's thought experiments show precisely that. Putnamesque Twin-Earth scenarios establish the ontic independence of intentionality from qualia, and hence the mutual independent supervenience or ontic dependence of qualia on intentionality, of qualia supervening on a thought's intentional states, rather than as Chalmers would have it, the other way around. ${ }^{25}$ The qualia or phenomenological thought content of Earth and TwinEarth counterpart psychological subjects are supposed to be identical (*Water!*), but they intend different things on Earth $\left(\mathrm{H}_{2} \mathrm{O}\right)$ and Twin-Earth $(\mathrm{XYZ}){ }^{26}$

More crucially, even if intentional relations supervene on purely physical properties, leaving phenomenological properties or the lived-through experience of qualia out of account, this does not preclude intentional relations also ontically or metaphysically emerging from instantiations of physical properties, in the sense that intentional relations may have higher-order properties that cannot be adequately reductively analyzed or explained away in terms of extra-intentional properties, whether physical or qualia-derived. ${ }^{27}$

\section{References}

Anscombe, G. E. M. (1965). The Intentionality of Sensation: A Grammatical Feature. In R. J. Butler (Ed.), Analytic Philosophy: Second Series (pp. 158-180). Oxford: Basil Blackwell.

\footnotetext{
${ }^{25}$ Hilary Putnam (1975, especially pp. 223-227) and Putnam (1981, especially pp,18-25). See also the papers collected in Andrew Pessin and Sanford Goldberg (1996) and Christopher Norris (2002).

${ }^{26}$ I follow Hector-Neri Castañeda's asterisk *...* convention for indicating the content of Husserlian noemata. See Castañeda (1975, p. 19).

27 See Jacquette (2006a).
} 
Berkeley, G. (1998). A Treatise Concerning the Principles of Knowledge. Oxford: Oxford University Press.

Brentano, F. (1874). Psychologie vom empirischen Standpunkt. Leipzig: Duncker und Humblot.

Brentano, F. (1995). Descriptive Psychology, translated and edited by B. Müller. London and New York: Routledge.

Castañeda, H. N. (1975). Thinking and Doing: The Philosophical Foundations of Institutions. DordrechtBoston: D. Reidel Publishing Company.

Chalmers, D. J. (1996). The Conscious Mind: In Search of a Fundamental Theory. Oxford: Oxford University Press.

Feigl, H. (1967). The 'Mental' and the 'Physical': The Essay and a Postscript. Minneapolis: University of Minnesota Press.

Fodor, J. A. (1987). Psychosemantics: The Problem of Meaning in the Philosophy of Mind. Cambridge, Mass.: MIT/Bradford Books.

Hume, D. (1978). In Selby-Bigge (Ed.), A treatise of human nature (pp. 1739-1740). Oxford: The Clarendon Press.

Jacquette, D. (1985). Sensation and Intentionality. Philosophical Studies, 47, 429-440.

Jacquette, D. (1987). Twardowski on Content and Object. Conceptus: Zeitschrift für Philosophie, Österreichische Philosophen und ihr Einfluss auf die Analytische Philosophie der Gegenwart, 21(2), 193-199.

Jacquette, D. (1991). The Origins of Gegenstandstheorie: Immanent and Transcendent Intentional Objects in Brentano, Twardowski, and Meinong. Brentano Studien, 3(1990-1991), 277-302.

Jacquette, D. (2002). Brentano's Scientific Revolution in Philosophy. Origins: The Common Sources of Analytic and Phenomenological Traditions. Southern Journal of Philosophy, Spindel Conference Supplement, 40, 193-221.

Jacquette, D. (2001). Fin de Siècle Austrian Thought and the Rise of Scientific Philosophy. History of European Ideas, 27, 307-315.

Jacquette, D. (2006a). Twardowski, Brentano's Dilemma, and the Content-Object Distinction. In A. Chrudzimski \& D. Lukasiewicz (Eds.), Actions, Products, and Things: Brentano and Polish Philosophy (pp. 9-33). Frankfurt: Ontos.

Jacquette, D. (2006b). Supervenience of Qualia and Intentionality. Philo: A Journal of Philosophy, 9, 145164.

Jacquette, D. (2009). Philosophy of Mind: The Metaphysics of Consciousness. London: Continuum.

Jacquette, D. (2010a). Logic and How it Gets That Way. Durham: Acumen.

Jacquette, D. (2010b). Metaphysics of Meinongian Value Theory. Meinong Studies, 4, 53-86.

Levinas, E. (1998). Intentionality and Sensation. In Discovering Existence with Husserl (pp. 135-150). Evanston: Northwestern University Press.

Norris, C. (2002). Hilary Putnam: Realism, Reason and the Uses of Uncertainty. Manchester: University of Manchester.

Pessin, A., \& Goldberg, S. (1996). The Twin Earth Chronicles: Twenty Years of Reflection on Hilary Putnam's 'The Meaning of Meaning'. Armonk: M. E. Sharpe.

Putnam, H. (1975). The Meaning of Meaning. In Language and Reality, Philosophical Papers, Vol. 2 (pp. 215-271). Cambridge: Cambridge University.

Putnam, H. (1981). Reason, Truth and History. Cambridge: Cambridge University.

Rorty, R. (1979). Philosophy and the Mirror of Nature. Princeton: Princeton University.

Schopenhauer, A. (1966). The World as Will and Representation [Die Welt als Wille und Vorstellung, 1859], 2 vols., translated by E.F.J. Payne. New York: Dover Publications.

Twardowski, K. (1977). Zur Lehre vom Inhalt und Gegenstand der Vorstellungen [1894]. The Hague: Martinus Nijhoff.

Wittgenstein L. (1989). Philosophical Investigations. $3^{\text {rd }}$ edition, translated by G.E.M. Anscombe. New York: Macmillan Publishing Company. 